\title{
Saving the Last Human Children
}

\section{Julie Rammal*}

Founder and Owner JSPORT, Holistic Trainer and Practitioner, Fitness Marketing Consultant, USA

*Corresponding Author: Julie Rammal, Founder and Owner JSPORT, Holistic Trainer and Practitioner, Fitness Marketing Consultant, USA.

Received: October 09, 2019; Published: October 18, 2019

In this and in the future era, we are seeing an immense evolvement of the human child. Their behaviour, thinking, emotions, social and relationship behaviour, eating, sleeping, and movement cycles are completely different from the older children generations. As a result, the classical child from decades ago is now being evolved to a semi robotic child. This is causing numerous unforeseen problems in: obesity, health, creativity, behaviour, and performance.

The classical child, was the child who lived in a world without the mega trend of electromagnetic gadgets such as the: ipad, cell phone, computers etc... They would play with traditional wooden toys, creatively draw, play in the nature, have friends, pets, and be well connected to their nature and environment. This was seen and lived by less then 100 years ago! A simple cloud, star, or the sun would fascinate them beyond imagination and curiosity. They were entertained with art, music, theatre, ceremonies, family events etc... The classical child ate natural foods, that were less or not industrialized, artificially coloured and promoted to eat. They were exposed to less media, propaganda, advertisement, and were guided more by parents and families. Their movements were natural, as they enjoyed running, dancing, football, jumping, gymnastics, and perhaps engaged in specialized sport such as: martial arts, swimming, fishing, hunting etc...The classical child is almost extinct, and worst to come is that the new child era is not prepared for the changed that they are exposed to.

The new child in our electronic era is the exact opposite. This child lives in a semi virtual world, where their mind is in union with another electronic gadget such as the ipad, cell phone, or computer. They might be wired to 1-2 electronic devices daily, and their parents are wired to much more. They move much less then the classical child, and movement seems to be a forced effort where parents tell their children to exercise. They might be enrolled in special fitness, or sport classes, or simply not be moving enough. This child is exposed to multiple brands of food, confusing their taste buds of what they should and should not eat. They are entertained with robotic toys, movies, trendy songs, virtual games, and some are already geared to money. Their sleeping cycles may also be altered. Their emotions, and behaviour are more aggressive, less disciplined, less ethical and respectful, and emotionally they are not as in tune with themselves as the classical child. The new child is dramatically affected from the new era of movement, where the increase rate of children seeing: psychologists, therapists, dieticians, and other health care professionals to re-balance their body, mind, and spirit are rising. This new child will later evolve to perhaps not being a child, but a dis-connected child who is connected to a world of electromagnetic gadgets. Leaving them with less emotion, less connection to themselves, external world, and facing tremendous health issues as they continuously connect to electronics. They will face a decrease in: creativity, imaginations, thinking and leave their lives to be lead by robots, and electronics. As a result, they will live their lives for others, and not be following their dreams, passions, imagination creating leaders, and change makers in history.

The solution lies in balancing in between the modern and classical era of time. Children must adapt to the new era to survive, however; they do not need to adapt to everything in their external world. They should only use and grasp what is added positive value for their body and mind and leave out toxic things that dis-connect them from their childhood age. They should engage in as much sport, natural activities, outdoor activities, and make sure that they are truly living their childhood that includes creativity, play, fun, exercise, healthy balanced meal plans, family and friends, and try to connect to nature as much as possible. 
In conclusion, if the new child does not properly adapt to the new era they will get absorbed into a world they are not prepared for. They will lose from happiness, joy, compassion, love as they grow older and be prone to addictions. Children should be raised in a holistic environment that is well nurtured, supported, loved, and friendly allowing them to grow and fulfil their dreams and passion.

Volume 2 Issue 11 November 2019

(C) All rights are reserved by Julie Rammal. 